\title{
Anthropometric multicompartmental model to predict body composition In Brazilian girls
}

\author{
Dalmo Machado ${ }^{1 *}$, Analiza Silva², Luis Gobbo ${ }^{3}$, Paula Elias $^{4}$, Francisco J. A. de Paula ${ }^{4}$ and Nilo Ramos ${ }^{5}$
}

\begin{abstract}
Background: Anthropometric models remain appropriate alternatives to estimate body composition of peripubertal populations. However, these traditional models do not consider other body components that undergo major changes during peripubertal growth spurt, with restrictions to a multicompartimental approach as a quantitative growth. DXA has great potential to determine pediatric body composition in more than one component (3-C), but has limited use in field settings. Thus, the aim of this study was to propose and validate an anthropometric model for simultaneous estimation of lean soft tissue (LST), bone mineral content (BMC) and fat mass (FM) in healthy girls, from a multivariate approach of densitometric technique, as the criterion method.
\end{abstract}

Methods: A sample of 84 Brazilian girls (7-17 years) was defined by chronological age and maturity offset. Whole total and regional DXA body scan were performed and, the components were defined (LST, BMC and FM) and considered as dependent variables. Twenty-one anthropometric measures were recorded as independent variables. From a multivariate regression, an anthropometric multicompartmental model was obtained.

Results: It was possible to predict DXA body components with only four predictive measurements: body weight (BW); supra-iliac skinfold (SiSk); horizontal abdominal skinfold (HaSk) and contracted arm circumference (CaCi) with high coefficients of determination and low estimation errors (LST =0.6662657 BW - 0. 2157279 SiSk - 0.2069373 HaSk + $0.3411678 \mathrm{CaCi}-1.8504187 ; \mathrm{BMC}=0.0222185 \mathrm{BW}-0.1001097 \mathrm{SiSk}-0.0064539 \mathrm{HaSk}-0.0084785 \mathrm{CaCi}+0.3733974$ and $\mathrm{FM}=0.3645630 \mathrm{BW}+0.1000325 \mathrm{SiSk}-0.2888978 \mathrm{HaSk}-0.4752146 \mathrm{CaCi}+2.8461916)$. The cross-validation was confirmed through the sum of squares of residuals (PRESS) method, presenting accurate coefficients (QRRESS from 0.81 to 0.93 ) and reduced error reliability (SPRESS from 0.01 to 0.30 ).

Conclusions: When sophisticated instruments are not available, this model provides valid estimates of multicompartmental body composition of girls in healthy Brazilian pediatric populations.

Keywords: Multicompartmental analysis, Children, Adolescents, Equation, DXA

\section{Background}

Assessment and monitoring of body composition in children and adolescents have great significance when there is the need to: a) study the prevalence of pediatric obesity, b) improve gender screening of body composition, c) track body composition from healthy childhood to adulthood, d) to assess FM changes over time in a given population [1], e) evaluate sport potential of young

\footnotetext{
* Correspondence: dalmo@usp.br

${ }^{1}$ School of Physical Education and Sport of Ribeirao Preto, University of Sao Paulo, Bandeirantes Ave. 3900, Monte Alegre, Ribeirão Preto, SP 14040-900, Brazil

Full list of author information is available at the end of the article
}

people, f) monitor training process, and g) prior knowledge of their physical characteristics [2].

Anthropometric based equations continue to be adequate alternatives to determine the body composition of pediatric populations. However, body composition assessment in children is not easy to measure, since the relationship between body components during growth is not constant as in adults [2]. The progress in the study of the quantitative human two-compartment model (2-C) comprising FM and fat-free mass (FFM) to 3-C template (water, fat and residual mass) and 4-C with the estimation of other components in addition to FM, total-body water 
(TBW), minerals and protein [3], has provided new ways for approaching the traditional body composition, especially when it involves peripubertal people.

Several pediatric anthropometric equations were developed using a model of $2-\mathrm{C}$ from the hydrostatic weighing $[4,5]$ and other densitometric techniques. However, this approach is based on assumptions of stable relationship for FFM density $\left(1.1 \mathrm{~g} / \mathrm{cm}^{3}\right)$ and FFM hydration $(73.2 \%)$. These values are stable in adults, but vary substantially during growth $[6,7]$. In fact, from birth to adolescence bone mineral and protein increase whereas TBW decreases thus raising FFM density until reaching the adult value when the chemical maturity profile is reached [6].

Therefore, body composition models have a multicompartmental approach, as the reference method, which accounts for the variability of the main FFM components due to age and maturational changes, resulting in more valid equations [1]. Even using 4-C models, several anthropometric models have been developed to estimate one body component, usually FM for pediatric populations. However, it could be possible to estimate other components such as water, protein, and mineral. In addition to using DXA as the reference method to develop anthropometric models, lean-soft tissue (LST), FM, and bone mineral content (BMC) could also be determined by using a multivariate regression model. When conceived in a multivariate pattern, considering appropriately all important factors, the likelihood to create robust models is attainable, increasing the predictive capacity and reducing errors of estimation [8-10].

Currently, DXA is recognized to have a great potential to determine body composition in pediatric studies [7], due to its ability to provide more than one component (3-C approach). However, the exposition to ionizing radiation, the equipment cost along with the lack of feasibility for large-scale use limits its applicability in field settings (home, school environments, and sport clubs). Consequently, simple solutions to estimate body composition in children from anthropometric techniques including skin folds, bone breadth and circumferences have been widely used and are preferred in different contexts [1]. These alternatives are more convenient due to their low costs, they require low level of personnel training, they are minimally invasive and have good scientific credibility [11].

Although conventional anthropometric methods are scientifically accepted, they do not distinguish bone from fat or muscles, a desirable fractionation of the body composition, in youth sports setting or clinical health. With the exception of the anthropometric models developed in our laboratory to determine LST, FM and BMC of boys [10-12], no proposal for girls was found able to estimate these 3 components, by somatic body measurements.

\section{Methods}

The aim of this study was to develop and validate a multicomponent anthropometric model to simultaneously estimate LST, BMC and FM in girls, from densitometry as a criterion method. This descriptive study design was conducted with an intentional sample from elementary school and swimming sporting centers, a social project for local children and adolescents.

\section{Study population}

The study followed a cross-sectional design and a sample of 84 girls between seven and 17 years recruited from a sports center $(n=69)$ and elementary schools $(n=15)$. The girls were healthy with no medical condition, without body parts amputated, no use of drugs or not under medical treatment that could affect metabolism, appetite or growth. All participants presented maturation status below the 5 Tanner stage, and body mass index (BMI) below pediatric obesity [13], except 7 cases slightly above each age limit.

\section{Study protocol}

All evaluations were performed at the Imaging Center of the University Hospital, Ribeirao Preto Medical School/ University of São Paulo, after an overnight fasting, in a single session; the same technicians performed all exams. Before the measurements, the subjects were asked to empty their bladders. A total-body DXA scan was performed according to manufacturer's guidelines. The anthropometric measures were taken according to the literature guidelines $(15,16)$, whose procedures are summarized below.

\section{The dependent variables}

Whole and regional body composition was estimated with a DXA Scanner Hologic (Discovery CI/WI, software version 11.2, Bedford, MA). The Lean Soft Tissue (LST, kg), Bone Mineral Content (BMC, kg) and Fat Mass (FM, kg) were determined (3-C) and considered as dependent variables.

\section{The independent variables}

The subject's body mass and height were measured with a digital scale (Welmy ${ }^{\circ}$, W 300 A, Santa Barbara d'Oeste, SP) and a hall fixed stadiometer (Physical Therapy Stadiometer - Terrazul ${ }^{\circ}$, Sao Paulo, SP), respectively. The skinfolds $(n=10)$, circumference $(n=10)$ and widths $(n=9)$, were measured by conventional procedures in the literature $[14,15]$ using Prime ${ }^{\curvearrowleft}$ equipment. Chronological age groups in decimal value were adjusted to the nearest integer [16]. To ensure the reliability of the results used in the models, intra evaluator technical error of measurement, absolute (TEM) and relative (TEM\%), were determined in subsequent days. Thirteen subjects were evaluated in duplicates for all variables used in this study, when the results were always within the expected tolerance limits [14] as shown below in Table 1. 
Table 1 Anthropometrics and DXA body composition measures in girls $(n=84)$, including absolute and relative TEM.

\begin{tabular}{|c|c|c|c|c|c|c|}
\hline & Min-Max & Mean & $\mathrm{Cl} 95 \%$ & SD & TEM & TEM\% \\
\hline Milesimal age (years) & $7-17$ & 11.64 & 11.11 to 12.16 & 2.42 & - & - \\
\hline PHV (years) & $-6.05-1.27$ & -3.16 & -3.48 to -2.83 & 1.51 & - & - \\
\hline \multicolumn{7}{|l|}{ DXA measures } \\
\hline Lean soft tissue (kg) & $12.55-53.39$ & 29.28 & 27.53 to 31.04 & 8.08 & 0.06 & 0.15 \\
\hline Bone mineral content (kg) & $0.74-2.55$ & 1.44 & 1.35 to 1.53 & 0.43 & 0.01 & 0.03 \\
\hline Fat mass (kg) & $5.56-46.05$ & 16.51 & 14.98 to 18.05 & 7.08 & 0.22 & 1.42 \\
\hline \multicolumn{7}{|l|}{ Anthropometrics } \\
\hline Stature (kg) & $116.0-178.0$ & 148.00 & 144.93 to 151.08 & 14.16 & 0.17 & 0.11 \\
\hline Body mass (kg) & $19.4-101.0$ & 46.84 & 43.78 to 49.89 & 14.06 & 0.27 & 0.29 \\
\hline $\mathrm{BMI}\left(\mathrm{kg} / \mathrm{m}^{2}\right)$ & $14.3-38.0$ & 20.98 & 19.97 to 21.99 & 4.65 & - & - \\
\hline Seat height (cm) & $70.0-105.0$ & 86.38 & 84.78 to 87.97 & 7.35 & 0.26 & 0.30 \\
\hline Triceps skinfold (mm) & $4.3-35.2$ & 15.74 & 14.22 to 17.26 & 6.99 & 0.12 & 1.09 \\
\hline Subscapular skinfold (mm) & $2.0-38.0$ & 12.66 & 11.04 to 14.27 & 7.43 & 0.04 & 0.28 \\
\hline Suprailiac skinfold (mm) & $2.5-54.0$ & 17.56 & 15.32 to 19.80 & 10.34 & 0.35 & 2.27 \\
\hline Horizontal abdominal Skinfold (mm) & $5.8-60.0$ & 21.57 & 19.43 to 23.72 & 9.89 & 0.82 & 4.20 \\
\hline Thigh skinfold (mm) & $9.8-58.0$ & 23.76 & 21.78 to 25.74 & 9.13 & 0.63 & 3.39 \\
\hline Media calf skinfold (mm) & $4.1-33.0$ & 16.70 & 15.25 to 18.15 & 6.69 & 0.23 & 1.88 \\
\hline Relaxed arm circumference $(\mathrm{cm})$ & $16.0-36.0$ & 23.03 & 22.20 to 23.20 & 3.83 & 0.31 & 1.35 \\
\hline Contracted arm circumference $(\mathrm{cm})$ & $16.7-36.8$ & 23.97 & 23.18 to 24.77 & 3.67 & 0.08 & 0.30 \\
\hline Waist circumference (cm) & $48.0-106.3$ & 64.58 & 62.68 to 66.48 & 8.75 & 0.37 & 0.56 \\
\hline Abdominal circumference $(\mathrm{cm})$ & $52.0-117.0$ & 70.45 & 68.21 to 72.69 & 10.32 & 0.48 & 0.67 \\
\hline Hip circumference (cm) & $59.0-118.5$ & 83.25 & 80.70 to 85.80 & 11.74 & 1.33 & 1.50 \\
\hline Thigh circumference (cm) & $30.0-68.0$ & 46.10 & 30.00 to 68.00 & 7.17 & 0.70 & 1.47 \\
\hline Calf circumference $(\mathrm{cm})$ & $21.0-42.0$ & 30.67 & 29.77 to 31.57 & 4.15 & 0.11 & 0.33 \\
\hline Bi-acromial breadth (cm) & $17.0-55.7$ & 32.14 & 31.19 to 33.09 & 4.38 & 0.22 & 0.61 \\
\hline Bi-iliac breadth (cm) & $17.0-33.6$ & 24.00 & 23.37 to 24.63 & 2.92 & 0.22 & 0.86 \\
\hline Biepicondylar humerus breadth (cm) & $4.1-6.9$ & 5.55 & 5.43 to 5.67 & 0.57 & 0.01 & 0.18 \\
\hline Biepicondylar femur breadth (cm) & $4.1-11.5$ & 8.32 & 8.12 to 8.53 & 0.94 & 0.02 & 0.17 \\
\hline
\end{tabular}

SD, Standard deviation, Cl Confidence interval, Min-Max minimum - maximum, TEM absolute technical error of measurement, TEM\% relative technical error of measurement, DXA Dual-energy X-ray absorptiometry, $P H V$ years for peak height velocity

Their maturity offset was determined by gender-specific regression to predict the years for Peak Height Velocity (PHV) according to the following equation [17] for girls:

$$
\begin{aligned}
\text { PHV }= & -9.376+0.0001882(\mathrm{Lh} \times \mathrm{Sh})+0.0022(\mathrm{~A} \times \mathrm{Lh}) \\
& +0.005841(\mathrm{~A} \times \mathrm{Sh})-0.002658(\mathrm{~A} \times \mathrm{Wt}) \\
& +0.07693((\mathrm{Wt} / \mathrm{Ht}) \times 100)
\end{aligned}
$$

Where: Lh stands for legs height (cm), Sh stands for seating height (cm), A stands for age (years), Wt stands for body mass ( $\mathrm{kg})$, and Ht stands for height (cm).

\section{Statistical analysis}

Interaction terms for ethnicity (Brazilians are highly intermingled) by anthropometric variables and sports activities (initial swimming practitioners) by anthropometric variables were tested and a nonsignificant differences was found ( $p=0.238$ ), allowing the use of the entire sample for subsequent analysis.

A sampling design was planned to set the desired maximum error $(\varepsilon)$ with some degree of confidence $\left(Z_{y}\right)$ from the prior knowledge of the population variability $\left(\sigma^{2}\right)[18]$. In this case, a multiethnic classic study values [19] describing girls body composition of different populations was used as reference values. The highest variability was observed in FM estimated by DXA, for all that ages (6-18 years), similarly to the sample ages of this study (7-17 years). From the estimation of the predetermined error (between 2.25 and $2.0 \%$ ) and confidence interval (0.90 to 0.95$)$, the ideal $\mathrm{n}$ for our study was defined by the equation [18]: 


$$
n=\left[\frac{Z_{y} S}{\varepsilon}\right]^{2}
$$

The minimum sample values $(n=74)$, setting for $\varepsilon=2.25$ and $\gamma=0.95$ and the estimated value of FM to $\sigma=9.84 \mathrm{Kg}$ was overcome by our sample $(\mathrm{n}=84)$, from the standard deviation $(s)$ obtained of that (Hispanic group) reference sample [19].

\section{Multicompartmental anthropometric equation development}

As earlier procedures [11] multivariate regression model $\left({ }_{\mathbf{n}} \mathbf{Y}_{\mathbf{m}}={ }_{\mathbf{n}} \mathbf{X}_{(\mathbf{r}+\mathbf{1})(\mathbf{r}+\mathbf{1})} \boldsymbol{\beta}_{\mathbf{m}}+{ }_{\mathbf{n}} \boldsymbol{\varepsilon}_{\mathbf{m}}\right)$ by diagonal mutual analysis, parameter estimation and the least squares errors method was used [8] by R-Free Software. Previously, a criteria for selection and reduction of independent variables was conducted from the following steps: a) principal component analysis and model adequacy (Kaiser-Meyer-Olkin) and Sphericity test (Bartlett); b) univariate regression (stepwise) to determine all common independent variables for each dependent variable (LST, BMC and FM), with significance less than 5\%; c) multivariate analysis to estimate the parameters and Pillai approximation method for displaying possible variables exclusions; e) testing of remaining model (enter - univariate method), with estimated values of VIF $(<10.0)$ and multicollinearity $(\mathrm{L}<1000)$ maximum permitted; f) adjustments by Pillai approach to test the $\mathrm{F}$ values; g) set the number of independent variables, with high coefficients of determination $(r \approx 0.90)$. Then $\beta$ parameters (multivariate) were determined, with the proposition of equations and residual distribution for each dependent variable. A similar procedure was earlier conducted in boys [10].

The PRESS statistic was used to measure the efficiency of a predictive equation, when applied to independent samples [20], that is, when used to estimate within the same sample. The process may be understood as design efficiency in estimating the actual parameters by a virtual simulation. In the case of this study, the error was determined by the result of observed Y - Y' (estimated). For validation: a) the correlation coefficients were estimated between predicted and measured values, and b) cross-validation by PRESS method and coefficients of determination ( $Q_{\text {PRESS }}^{2}$ ) and error $\left(S_{\text {PRESS }}\right)$ was conducted for each dependent variable, according to the Johnson and Wichern [8] recommendations.

Other statistical procedures included descriptive analysis with calculation of mean and standard deviation and confidence interval (95\%) and coefficient of variation, used to express milesimal age, DXA and anthropometric dimensions of girl's body components.

\section{Results}

Table 1 provides anthropometric and body composition measures, including range (minimum - maximum), the confidence interval $(95 \% \mathrm{CI})$, and absolute and relative TEM of the measures expressing the main characteristics of the study sample.

The Kaiser-Meyer-Olkin test (0.882) was used as a measure of adequacy of the sample $\left(X^{2}=2961.11\right)$ with $p<0.001$, indicating suitability of the method in the treatment of the data. The commonalities test ranged from 0.689 to 0.927 for the 22 variables entered into the analysis. The matrix indicated coefficients of correlation from weak $(r=0.20)$ to very high $(r=0.95)$ between the 21 independent variables (size measures, skinfolds, circumferences, bone breadths) and the dependent variables (data not shown). To reduce variables of the model, univariate regression was performed (stepwise) in order to select the common dependent variable to the three components (LST, BMC and FM) since common selection occurred at least twice, maintaining the highest possible coefficients.

The high correlation between the independent variables shows the existence of multicollinearity, which brings undesirable consequences for the inferential analysis (24). From the univariate regression (stepwise), the number of remaining variables to LST $(n=7)$, BMC $(n=5)$ and FM $(\mathrm{n}=4)$ showed high $\mathrm{r}_{\text {adj }}^{2}(0.90$ to 0.94$)$, while multicollinearity varied from low $(\mathrm{L}=55.0)$ to moderate $(\mathrm{L}=275.0)$ for the independent common variables for the three dependents variables (Table 2), a multivariable analysis.

From the multivariate regression model, statistical significance (Pillai) of the $\mathrm{F}$ values (for $<2.2 \mathrm{e}^{-16}$ implies the notation $<2.2 \times 10^{-16}$ ) was found for four predictor anthropometric variables.

The precision of the model was initially tested in univariate analysis (Enter method) while maintaining low multicollinearity and high correlation coefficients between measured and predicted values (Table 3). Multicollinearity was low, ranging from tolerance for eigenvalues $(L<100)$, VIF $(<10.0)$, and the determination of simple coefficients $\left(\mathrm{r}^{2}\right)$ and adjusted $\left(\mathrm{r}^{2}\right.$ adj).

The graphic expression of dispersion and the correlation between predicted and measured values is shown in Fig. 1.

The results of the residuals sum of squares $\left(\mathrm{P}_{\mathrm{RESS}}\right)$, the coefficient of determination PRESS ( $Q_{\text {PRESS }}^{2}$ ) and the standard deviation of PRESS (S $S_{\text {PRESS }}$ ) obtained for each dependent variable, were also expressed (Table 3 ). These results suggested that the multivariate prediction model is valid for LST, BMC and FM since it indicates consistency with the conditions defined in the method for $\mathrm{Q}_{\text {PRESS }}^{2}$ be close to "1" and S PRESS close to "0". Thus, the final model for each dependent variable including Residual Tissue (RT) as the difference for the BW, can be stated as: 
Table 2 Univariate regression and multicollinearity for selecting common independent variables at least twice (bold)

\begin{tabular}{|c|c|c|c|c|c|c|}
\hline \multicolumn{2}{|c|}{ Lean soft tissue } & \multicolumn{3}{|c|}{ Bone mineral content } & \multicolumn{2}{|l|}{ Fat mass } \\
\hline Variables & Eigenvalues & Variables & Eigenvalues1 & Eigenvalues2 & Variables & Eigenvalues \\
\hline Wt & 0.255 & $\mathrm{Ht}$ & 0.275 & & Wt & 0.110 \\
\hline SiSk & 0.041 & Wt & 0.140 & 0.275 & HaSk & 0.027 \\
\hline HaSk & 0.031 & $U m_{A b}$ & 0.010 & 0.112 & $\mathrm{CaCi}$ & 0.006 \\
\hline $\mathrm{WaCi}$ & 0.018 & PHV & 0.002 & 0.009 & $\mathrm{BiAc}$ & 0.002 \\
\hline TrSk & 0.010 & SiSk & 0.001 & 0.001 & & \\
\hline $\mathrm{CaCi}$ & 0.002 & & & & & \\
\hline MiWa & 0.002 & & & & & \\
\hline$r_{a d j}^{2}=0.946$ & $L=127.5$ & $r_{\text {adj }}^{2}=0.905$ & $L=275.0$ & $L=275.0$ & $r_{a d j}^{2}=0.904$ & $L=55.0$ \\
\hline
\end{tabular}

Wt weight, Si Supra-iliac, Sk Skinfold, Ha Horizontal abdominal, Wa Waist, Ci Circumference, Tr Triciptal, Ca Contracted armm, MiWa Middle waist, Ht Height, $U m_{A b}$ Umbilical abdominal, PHV years for peak height velocity, BiAc bi-acromial breadth, $r_{\text {adj }}^{2}$ adjusted coefficient of determination, $L$ multicollinearity

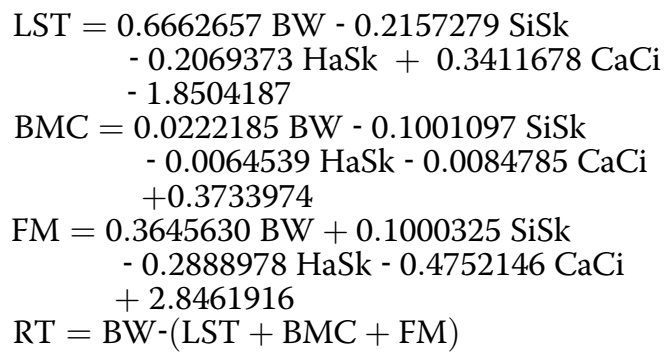

Where: $L S T=$ lean soft tissue; $B M C=$ bone mineral content; FM = fat mass; $R T=$ residual tissue; $B W=$ body weight (kg); SiSk = supra-iliac skinfold $(\mathrm{mm}) ; \mathrm{HaSk}=$ horizontal abdominal skinfold $(\mathrm{mm}) ; \mathrm{CaCi}=$ contracted arm circumference $(\mathrm{cm})$.

\section{Discussion}

As novel finding in this study, anthropometric models were developed and validated to determine FM, LST and BMC in a female pediatric sample, using DXA as the reference method. Adult models are not expected to describe or estimate body composition in children and adolescents [21]. Limitations in current available techniques to evaluate body composition hampers, in several circumstances, the measurement of the main body compartments in the molecular level [7]. In our study, DXA returned absolute measures of LST, BMC and FM in a 3-C approach, which represents estimation advantages by minimizing error in a single scan. However, DXA is almost restricted to the medical environment. Consequently, anthropometry is an alternative method since the anthropometric model was valid to estimate body

Table 3 Parameters, precision and validity of multicomponent anthropometric model, to predict body composition in peripubertal girls

\begin{tabular}{|c|c|c|c|c|c|c|}
\hline & $\beta$ LST (kg) & $\beta$ BMC (kg) & $\beta \mathrm{FM}(\mathrm{kg})$ & F num. & $\mathrm{p}(>\mathrm{F})$ Pillai & Sig. \\
\hline Intercept & -1.8504187 & 0.373397388 & 2.8461916 & & & \\
\hline Weight & 0.6662657 & 0.022218491 & 0.3645630 & 890.28 & $<2.2 \mathrm{e}^{-16}$ & $* * *$ \\
\hline SiSk & -0.2157279 & -0.010010969 & 0.1000325 & 54.97 & $<2.2 \mathrm{e}^{-16}$ & $* * *$ \\
\hline HaSk & -0.2069373 & -0.006453997 & 0.2888978 & 6.56 & 0.0005247 & $* * *$ \\
\hline $\mathrm{CaCi}$ & 0.3411678 & 0.008478514 & -0.4752146 & 2.84 & 0.0435579 & * \\
\hline
\end{tabular}

Precision

\begin{tabular}{|c|c|c|c|c|c|}
\hline$r^{2}$ & 0.9392 & 0.8578 & 0.9056 & & \\
\hline$r^{2}(\operatorname{adj})$ & 0.9361 & 0.8506 & 0.9008 & & \\
\hline SEE (kg) & 2.0422 & 0.1012 & 2.2300 & & \\
\hline ross-validation & & & & (>) VIF & Eigenvalue \\
\hline PRESS & 329.300 & 0.809 & 392.852 & 7.282 & 89.000 \\
\hline$Q_{\text {PRESS }}^{2}$ & 0.9272 & 0.8112 & 0.8872 & & \\
\hline SPRESS & 0.2718 & 0.0142 & 0.2966 & & \\
\hline
\end{tabular}

LST Lean soft tissue, BMC Bone mineral content, FM Fat mass, Sig. = 0,000 ‘***; 0,001 ‘**’; 0,05 ‘*', SiSk Supra-iliac skinfold, HaSk Horizontal abdominal skinfold, $\mathrm{CaCi}$ Contracted arm circumference, $r^{2}$ coefficient of determination (observed and cross-predicted), $r^{2}$ (adj) adjusted coefficient of determination, SEE residual standard error of estimate, PRESS sum of squares of residuals, $Q_{P R E S S}^{2}$ press coefficient of determination, SEE $E_{P R E S S}$ press standard error of estimate, VIF Variance inflation factor, Eigenvalue characteristic values of regression 

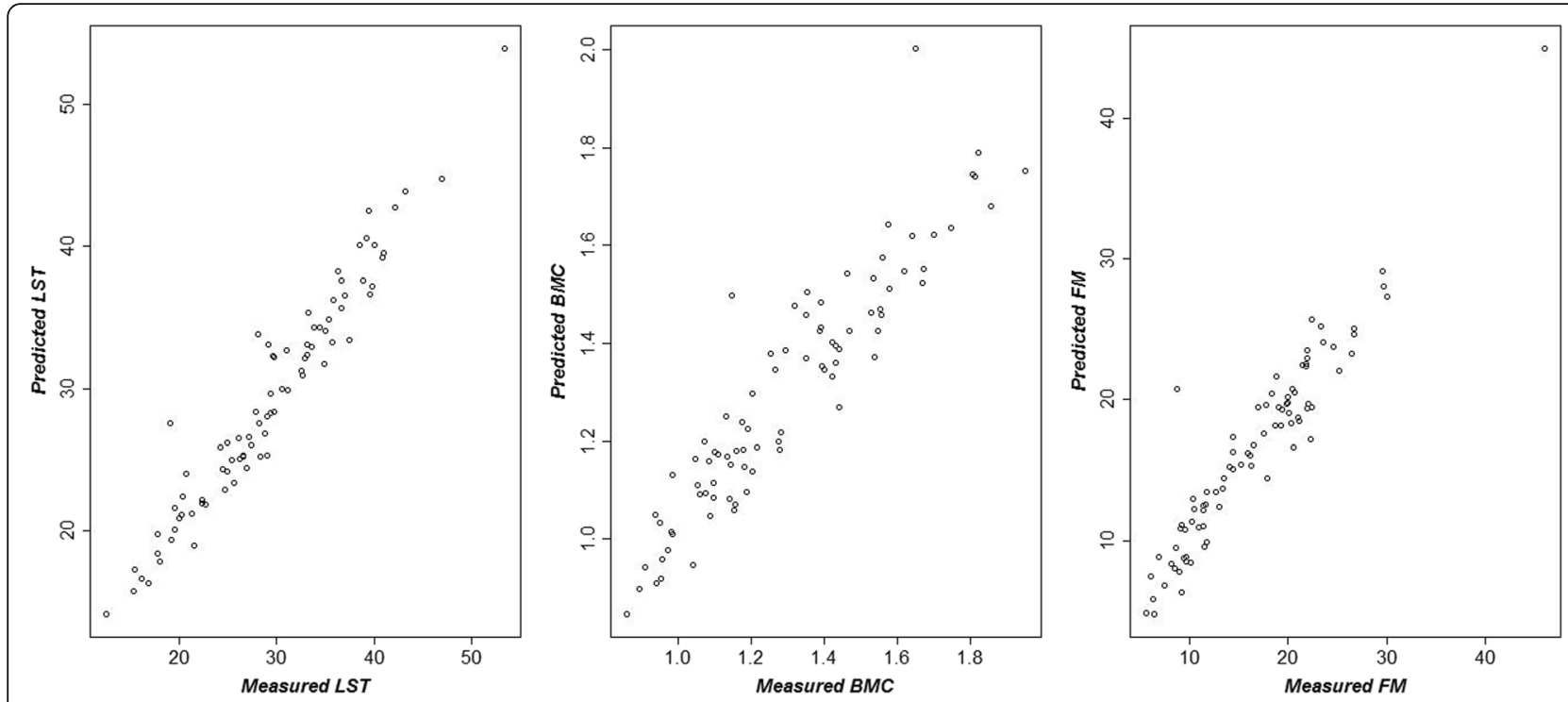

Fig. 1 Dispersion between measured and predicted values of lean soft tissue (LST), bone mineral content (BMC) and fat mass (FM) of girls

composition using DXA as reference. Greater predictive accuracy was obtained through four anthropometric variables to simultaneously predict LST, BMC and FM.

DXA has great potential in pediatric studies, low level of ionizing radiation exposure, convenience and speed in the estimation of multicomponent body, which allows better interpretation of BC during growth and appropriate association with anthropometric estimates. Since the 80 s, predictive equations of FM and FFM by anthropometry and BIA, using DXA (or other 3-C models) and 4-C as criterion methods [22], have been used, although none try to predict more than one component, otherwise only FM or FFM.

The known pediatric equations of Slaughter and colleagues used skinfolds models derived from a 4-C model [23]. However, lower coefficients of determination $\left(r^{2}=0.88\right)$ and greater standard errors of estimation $(\mathrm{SEE}=3.80 \%)$ were found for FM determination, when compared to our results, $\left(r^{2}>.94\right.$; SEE $<2.25 \%$; $\mathrm{S}_{\text {PRESS }}=0.01$ to 0.30$)$ and no cross-validation was provided.

In ages younger than 10 years, the dispersion of body tissues tends to be lower than in subsequent ages [19]. This implies that the pre pubertal growth and maturation are quite compatible. At this age, the change in hormonal concentration that occurs during sexual maturation has not yet started [12]. The density of FFM is influenced in large part by bone mineral because the density of bone is markedly higher than that of other components of the FFM. During this special period of life there is an unstable relationship between BMC and muscle mass in comparison to adulthood [24]. In addition, the increase of other body components during growth [25] is markedly higher in FM until about 13 years, registering increases from childhood to adulthood of $17 \%$ in girls and $15 \%$ in boys. When presenting exponential reduction, no significant changes are found for the three components after age 20 in girls and age 21-22 in boys [26].

Besides extending to girls with high body mass, this new methodology overcome traditional limitations of bi-compartmental models by offering an alternative multivariate analysis, a new way for a comprehensive approach $[7,21,27,28]$. The observed high coefficients values and low errors estimation (Table 3 ) reflected a usual good validity when using our laboratory proposed equations [2]. Several factors can affect the accuracy of a predictive equation as: the dependent variable validity; accuracy of predictive variables; statistical intra and inter-biological relationship between independent and dependent variables; appropriated use of statistical methods to formulate the equation; and adequate sample size [29]. The necessary conditions for the proposition of a predictive model must meet statistical requirements for a safe and reliable model/equation.

Assumptions for good predictive models of body composition recommend that models should be proposed for a wider clinical application [30], make valid assumptions in relations between the components [28], i.e., if relations between FFM, FM and TBW are constant for all ages. Some equations proposed are more well-founded descriptions and specific to predict only one component [31], or restricted age range [32]. When it involves wider range age (5-19 years), adopt sophisticated laboratory techniques and expensive procedures [33]. Furthermore, the inclusion of independent variables with strong statistical and biological relationship with the variable of 
interest, certainly increases its predictive power [28]. The internal validation method PRESS [34], as in our equations, confirms the effectiveness of the model in predicting the body components with high internal validity, high coefficients of determination $\left(\mathrm{Q}_{\text {PRESS }}^{2}=0.81 \mathrm{a}\right.$ $0.93)$ and low prediction errors $\left(S_{\text {PRESS }}=0.01\right.$ a 0.30$)$.

The anthropometric measurements are obtained easily and at a low cost while preserving the accuracy and low error to be considered as an alternative to DXA [35]. We recognize as limitation of this study that DXA is not a gold standard for pediatric body composition models. But conversely, the four compartments (4-C models) is the current state of the art method since it considers the variability of the main FFM components [36]. However, it is also subject to propagation of measurement errors, is time consuming, and requires sophisticated and highly specialized technical equipment. Moreover, it is restricted to research facilities and has high costs, making it difficult to use in large samples [37]. Nevertheless, DXA has been used by various researchers to develop pediatric equations $[19,38-41]$, therefore considered as a valid and reliable method [42]. Other limitation consider that the accurate measurement of LST, especially in athletes, requires strict observation of hydration, which may affect DXA assessment [43]; as well the menstrual cycle of girls [44], not controlled in this study. However, the girls in the study had a low level of maturation (PHV $=-3.16)$ and were not athletes, minimizing possible errors of analysis.

Additionally, nutritional data, social or economic status, hereditary or level of sports training were not controlled in this study and may interfere with the female body composition. The small sample size may compromise the accuracy of the models since the sample may not have a well balance representation of age and adiposity levels. In addition, ethnic differences in this sample, although comprising a highly mixed-race, may also limit the generalization of these equations for other populations as the number of females in each ethnic group was not well balanced [2]. Although racial and sports practice showed no interactions terms with anthropometric variables in explaining the reference variables, research is required to test the accuracy of the proposed model for other ethnic groups. Finally, for longitudinal body composition assessment, the accuracy of these models requires further validation, or estimates for age groups.

\section{Conclusions}

The goal of this study to develop and validate an anthropometric predictive model to simultaneously estimate LST, BMC and FM was achieved. These models provide a practical, low cost, and reliable tool in assessing body composition of a specific female pediatric population. These models can be used to determine and monitor body growth in peripubertal girls, either to assess health indicators (i.e., overweight control, obesity and the associated risks), or improve sports performance (i.e., body adequacy and physical preparation for sports). However it should be tested and validated for other ethnic groups.

The internal validation method PRESS [34] confirms the effectiveness of the model in predicting the body components with high internal validity, with high coefficients of determination and low prediction errors. These models may be a valid alternative to estimate body composition in girls and allow application in clinical environment or field settings.

\section{Abbreviations \\ $Z_{y}$ : degree of confidence; $\varepsilon$ : maximum error; $\sigma^{2}$ : variance; 2-C: two-compartment model; A: age (years); BMC: Bone mineral content; BMI: Body mass index; BW: Body weight; CaCi: Contracted arm circumference; DXA: Dual energy X-ray absorptiometry; FFM: Fat-free mass; FM: Fat mass; HaSk: Horizontal abdominal skinfold; Ht: Height; L: multicollinearity; Lh: Legs height; LST: Lean soft tissue; PHV: Peak height velocity; PRESS: sum of squares of residuals; QPRESS: PRESS coefficients of determination; r: coefficients of correlation; SEE: Standard errors of estimation; Sh: Seating height; SiSk: Supra-iliac skinfold; SPRESS: PRESS error; TBW: Total body water; TEM\%: relative technical error of measurement; \\ TEM: absolute technical error of measurement; VIF: Variance inflation factor; Wt: body mass (kg); $\beta$ : beta parameter}

\section{Acknowledgments}

We are thankful for parents or guardians' permission and for children's participation in this study.

\section{Funding}

No funding was received

Availability of data and materials

All data is contained within the manuscript.

\section{Authors' contributions}

DM and LG contributed to the study design, DM, PE, FP were responsible for data collecting and analysis of data, AS, LG and NR contributed to the critical revision for publishing and English review. All authors read and approved the final manuscript version.

\section{Ethics approval and consent to participate}

Consent forms were obtained from the parents or guardians and the study followed the guidelines and regulations for human research. The approval was granted by the Ethics in Research Committee of the Faculty of Philosophy, Sciences and Letters of Ribeirao Preto, University of Sao Paulo (CAAE 13001913.9.0000.5407), which also adhere to the Helsinki Declaration.

Consent for publication

Not applicable.

\section{Competing interests}

The authors declare that they have no competing interests.

\section{Publisher's Note}

Springer Nature remains neutral with regard to jurisdictional claims in published maps and institutional affiliations.

\section{Author details}

${ }^{1}$ School of Physical Education and Sport of Ribeirao Preto, University of Sao Paulo, Bandeirantes Ave. 3900, Monte Alegre, Ribeirão Preto, SP 14040-900, Brazil. ${ }^{2}$ Exercise and Health Laboratory, CIPER, Faculdade de Motricidade Humana, Universidade de Lisboa, Lisboa, Portugal. ${ }^{3}$ Department of Physical Education, Universidade Estadual Paulista, Presidente Prudente, Ribeirao Preto, Brazil. ${ }^{4}$ Department of Internal Medicine, Ribeirao Preto Medical School, University of Sao Paulo, Ribeirao Preto, SP, Brazil. ${ }^{5}$ Department of Graduate and Specialty Studies, Coastal Carolina University, Conway, SC, USA. 
Received: 15 July 2017 Accepted: 7 December 2017 Published online: 21 December 2017

\section{References}

1. Mulazimoglu $O$. The relative age effect (RAE) in youth and professional soccer players in Turkey. Anthropologist. 2014;18(2):391-8.

2. Lohman TG, Hingle M, Going SB. Body composition in children. Pediatr Exerc Sci. 2013;25(4):573-90.

3. Sardinha LB. Functional Body Composition. Archives of Exercise in Health and Disease. 2012;3(3):183-7.

4. Deurenberg P, Pieters JJ, Hautvast JG. The assessment of the body fat percentage by skinfold thickness measurements in childhood and young adolescence. Br J Nutr. 1990;63(2):293-303.

5. Weststrate JA, Deurenberg P. Body composition in children: proposal for a method for calculating body fat percentage from total body density or skinfold-thickness measurements. Am J Clin Nutr. 1989;50(5):1104-15.

6. Wells JC, Fuller NJ, Dewit O, Fewtrell MS, Elia M, Cole TJ. Four-component model of body composition in children: density and hydration of fat-free mass and comparison with simpler models. Am J Clin Nutr. 1999;69(5):904-12.

7. Silva AM, Fields DA, Sardinha LB. A PRISMA-driven systematic review of predictive equations for assessing fat and fat-free mass in healthy children and adolescents using multicomponent molecular models as the reference method. Journal of obesity. 2013;2013:148696-6

8. Johnson RA, Wichern DW. Applied Multivariate Statistical Analysis. 5th ed. New York: Prentice Hall; 1992

9. Nogueira FE. Modelos de regressão multivariada. São Paulo: Universidade de São Paulo; 2007.

10. Machado DRL, Gobbo LA, Puggina EF, Petroski EL, Barbanti VJ: Anthropometric model to estimate body fat in boys using a multicompartmental approach. In: Children and Exercise XXVIII: The Proceedings of the 28th Pediatric Work Physiology Meeting. Volume 13, edn. Edited by Coelho-e-Silva MJ, Cupido-dosSantos A, Figueiredo AJ, Armstrong N, Ferreira JP: Routledge; 2013: 165-168.

11. Machado D, Oikawa S, Barbanti V. The multicomponent anthropometric model for assessing body composition in a male pediatric population: a simultaneous prediction of fat mass, bone mineral content, and lean soft tissue. Journal of obesity. 2013;2013:428135.

12. Machado DRL. Análise multivariada da composição corporal em jovens esportistas e não esportistas. São Paulo: Universidade de São Paulo; 2009.

13. Cole TJ, Bellizzi MC, Flegal KM, Dietz WH. Establishing a standard definition for child overweight and obesity worldwide: international survey. BMJ. 2000:320(7244):1240-3.

14. Norton K, Olds T. Antropométrica. Armed: Porto Alegre; 2005.

15. Lohman TG. Applicability of body composition techniques and constants for children and youths. Exercise and sport sciences reviews. 1986;14:325-57.

16. Healy MJR, Lovaic JA, Mandel SPH, Tanner JM, Schull WJ, Weiner JS: The individual and the group. In: Practical Human Biology. edn. Edited by Weiner JS, Lonnie JA. New York: Academic Press; 1981: 11-23.

17. Mirwald RL, Baxter-Jones AD, Bailey DA, Beunen GP. An assessment of maturity from anthropometric measurements. Med Sci Sports Exerc 2002:34(4):689-94

18. Bolfarine H, Bussab WO. Elementos de amostragem. Edgard Blücher: São Paulo 2005

19. Ellis KJ. Body composition of a young, multiethnic, male population. Am J Clin Nutr. 1997:66(6):1323-31.

20. Myers RH: Classical and modern regression with applications (Duxbury Classic). Duxbury Press, Pacific Grove 2000

21. Heymsfield SB, Lohman TG, Wang Z, Going SB. Human body composition. 2nd ed. Human Kinetics: Champaign; 2005.

22. Silva AM, Fields DA, Sardinha LB: A PRISMA-driven systematic review of predictive equations for assessing fat and fat-free mass in healthy children and adolescents using multicomponent molecular models as the reference method. Journal of obesity 2013, 2013 \%@ 2090-0708.

23. Slaughter MH, Lohman TG, Boileau RA, Horswill CA, Stillman RJ, Van Loan MD, Bemben DA. Skinfold equations for estimation of body fatness in children and youth. Hum Biol. 1988:60(5):709-23.

24. Fields DA, Goran MI, McCrory MA. Body-composition assessment via airdisplacement plethysmography in adults and children: a review. Am J Clin Nutr. 2002;75(3):453-67.

25. Minderico CS, Silva AM, Teixeira PJ, Sardinha LB, Hull HR, Fields DA. Validity of air-displacement plethysmography in the assessment of body composition changes in a 16-month weight loss program. Nutrition \& Metabolism. 2006:3(1):32-40.

26. Braillon PM: Annual changes in bone mineral content and body composition during growth. Horm Res 2002, 60(6):284-290 \%@ 0301-0163.

27. Sun SS, Schubert CM, Liang R, Roche AF, Kulin HE, Lee PA, Himes JH, Chumlea WC. Is sexual maturity occurring earlier among U.S. children? J Adolesc Health. 2005;37(5):345-55.

28. Heymsfield SB, Wang Z, Baumgartner RN, Ross R. Human body composition: advances in models and methods. Annu Rev Nutr. 1997:17:527-58.

29. Sun SS, Chumlea WCP: Statistical Methods.In: Human body composition. edn. Edited by Heymsfield SB, Lohman TG, Wang Z, Going BF. Champaign: Human Kinetics; 2005: 151-160

30. Kyle UG, Piccoli A, Pichard C. Body composition measurements: interpretation finally made easy for clinical use. Curr Opin Clin Nutr Metab Care. 2003:6(4):387-93.

31. Valente-dos-Santos J, Coelho-e-Silva MJ, Machado-Rodrigues AM, ElferinkGemser MT, Malina RM, Petroski ÉL, Minderico CS, Silva AM, Baptista F. Sardinha LB: Prediction equation for lower limbs lean soft tissue in circumpubertal boys using anthropometry and biological maturation. PloS one 2014, 9(9):e107219\%@ 101932-106203.

32. Fomon SJ, Haschke F, Ziegler EE, Nelson SE. Body composition of reference children from birth to age 10 years. Am J Clin Nutr. 1982:35(5 Suppl):1169-75.

33. Ellis KJ, Shypailo RJ, Abrams SA, Wong WW: The reference child and adolescent models of body composition. A contemporary comparison. Ann N Y Acad Sci 2000, 904:374-382.

34. Holiday DB, Ballard JE, McKeown BC. PRESS-related statistics: regression tools for cross-validation and case diagnostics. Med Sci Sports Exerc. 1995;27(4):612-20.

35. Sardinha LB, Teixeira PJ, Guedes DP, Going SB, Lohman TG. Subcutaneous central fat is associated with cardiovascular risk factors in men independently of total fatness and fitness. Metabolism. 2000:49(11):1379-85.

36. Wells JC, Williams JE, Chomtho S, Darch T, Grijalva-Eternod C, Kennedy K, Haroun D, Wilson C, Cole TJ, Fewtrell MS. Pediatric reference data for lean tissue properties: density and hydration from age 5 to $20 \mathrm{y}$. Am J Clin Nutr. 2010;91(3):610-8.

37. Goncalves EM, Silva AM, Santos DA, Lemos-Marini SH, de Oliveira SA Mendes-Dos-Santos CT, De-Mello MP, Guerra-Junior G. Accuracy of anthropometric measurements in estimating fat mass in individuals with 21-hydroxylase deficiency. Nutrition. 2012;28(10):984-90.

38. Goran MI, Driscoll P, Johnson R, Nagy TR, Hunter G. Cross-calibration of body-composition techniques against dual-energy $X$-ray absorptiometry in young children. Am J Clin Nutr. 1996;63(3):299-305.

39. Dezenberg CV, Nagy TR, Gower BA, Johnson R, Goran MI. Predicting body composition from anthropometry in pre-adolescent children. Int J Obes Relat Metab Disord. 1999:23(3):253-9.

40. Morrison JA, Guo SS, Specker B, Chumlea WC, Yanovski SZ, Yanovski JA. Assessing the body composition of 6-17-year-old Black and White girls in field studies. Am J Hum Biol. 2001;13(2):249-54.

41. Bray GA, DeLany JP, Volaufova J, Harsha DW, Champagne C. Prediction of body fat in 12-y-old African American and white children: evaluation of methods. Am J Clin Nutr. 2002;76(5):980-90.

42. Toombs RJ, Ducher G, Shepherd JA, De Souza MJ. The impact of recent technological advances on the trueness and precision of DXA to assess body composition. Obesity (Silver Spring). 2011;20(1):30-9.

43. Toomey CM, McCormack WG, Jakeman P. The effect of hydration status on the measurement of lean tissue mass by dual-energy $X$-ray absorptiometry. Eur J Appl Physiol. 2017;117(3):567-74.

44. Sharma S, JayanandManjhi, Rai D: Correlative study of EEG and Body Hydration across the Menstrual Cycle, vol. 1; 2012 